\title{
Interferon-induced progression of autoimmune thyroiditis with enlarged thyroid glands in gynecological patient: A case report and literature review
}

\author{
Ospan Mynbaev ${ }^{1,2 *}$, Marina Eliseeva ${ }^{2,3}$, Artem Chernov ${ }^{4}$, Ioannis Kosmas ${ }^{5}$, Andrea Tinelli ${ }^{6}$, \\ Victor Radzinsky ${ }^{2}$, Victor Tsarev ${ }^{1}$ \\ ${ }^{1}$ Moscow State University of Medicine \& Dentistry Named after A. I. Evdokimov, Moscow, Russia \\ ${ }^{2}$ Peoples' Friendship University of Russia, Moscow, Russia \\ ${ }^{3}$ The Institute of Reproductive Technologies AltraVita, Moscow, Russia \\ ${ }^{4}$ National Medical Academy of Post-Graduate Education Named after P. L. Shupik, Ministry of Health of Ukraine, Kyiv, Ukraine \\ ${ }^{5}$ Xatzikosta General Hospital, Ioannina, Greece \\ ${ }^{6}$ Division of Experimental Endoscopic Surgery, Imaging, Technology and Minimally Invasive Therapy, Department of Obstetrics \\ and Gynecology, Vito Fazzi Hospital, Lecce, Italy \\ Email: "ospanmynbaev@hotmail.com
}

Received 10 December 2012; revised 13 January 2013; accepted 22 January 2013

\begin{abstract}
A case report presents a progression of autoimmune thyroiditis with an abnormal enlargement of the thyroid glands and increased thyreotropin hormone concentration-associated with interferon treatment in human papillomavirus infected patient with the autoimmune thyroiditis and a daily L-thyroxin hormone replacement therapy background. Observation was supplemented with a brief review of literature and discussion. On the basis of this observation and a brief review of literature authors suggested that the potential adverse effects of interferon therapy are overbalanced than its benefits for gynecological patients, therefore any interferon treatment should be recommended with strict indications as well as after screening of conditions and functions of thyroid glands and other interferon target organs to avoid interferon treatment side effects. Practitioners especially gynecologists should inform their patients about pleiotropic interferon effects and its high frequent and wide range side effects before to start such kind of treatment.
\end{abstract}

Keywords: Autoimmune Thyroiditis; Human Papillomavirus; Interferon; Thyroid Glands

\section{INTRODUCTION}

Interferon (IFN) is widely used cytokine as an adjuvant treatment of malignant diseases such as melanoma [1], renal cell carcinoma [2,3], hairy cell leukemia [4], Kaposi's sarcoma [5]. It also has been extensively used to

\footnotetext{
"Corresponding author.
}

treat hepatitis B and C [6,7], as antiviral therapeutic agent.

Wide range of IFN treatment (IFN-TRT) side effects, due to pleiotropic mechanisms of its action, were described, including neuropsychiatric and neurobehavioral complications [8,9], IFN-induced depression [10], sexual dysfunctions [11], plural disturbances [12] and thyroiditis [13-15].

Fentiman et al. described a primary hypothyroidism in three patients with breast cancer during a trial of adjuvant IFN- $\alpha$-TRT [16]. Since IFN-induced thyroiditis (IIT) were recognized as one of common side effects of IFNTRT. The incidence of IFN-induced thyroid autoimmunity according to Oppenheim et al. ranged from $2.5 \%$ to $42 \%$, possibly depending upon dose and duration of IFNTRT and patient characteristics [17], whereas the rate of IIT by Tomer and Menconi was reached up to $40 \%$ in patients with hepatitis $\mathrm{B}$ and $\mathrm{C}$, including the rate of clinical manifestations of IIT up to $10 \%$ and subclinical autoimmune thyroiditis up to $30 \%$ [18].

IFNs have been also widely used to treat genital warts, although their benefits were not clear [19]. Recently Yang et al. systematically reviewed 12 randomized controlled trials involving 1445 patients and concluded that IFN tends to be a fairly well-tolerated when it was locally used than its systemic administration to treat patients with genital warts [20]. However side effects of IFN-TRT in gynecological patients were not described yet.

\section{CASE DESCRIPTION}

26-year-old patient with subtle layer acetowhite lesions around external ostium of cervix uteri had abnormal low 
grade Pap smear (CIN1). Repeat DNA human papilloma virus (HPV) tests presented a persisted high risk HPV infection (16 and 18 genotypes). Patient has been under a medical supervision of an endocrinologist since thyroid hypofunction and autoimmune thyroiditis (AIT) was diagnosed. A size of left thyroid gland lobule was $14.5 \mathrm{~cm}^{3}$ and right $-15.1 \mathrm{~cm}^{3}$ by means of ultrasound examination. A thyrotropin hormone (TSH) concentration was 0.88 $\mathrm{mIU} / \mathrm{L}$ (reference values $-0.4-4.5 \mathrm{mIU} / \mathrm{L}$ ). Patient had received a hormone replacement therapy with $75 \mathrm{mg}$ daily L-thyroxin and her condition was stable without AIT progression.

At the appointment a gynecologist due to cervical lesions with an abnormal low grade Pap smear (CIN1) and repeat DNA HPV positive tests decided to treat cervical lesions with conservative medications and prescribed several courses of IFN-TRT by turn. The treatment has continued before and after cryodestruction of cervical lesions and prolonged for 8 months but HPV persistence remained unchanged.

Patient received two courses of rectal suppository with IFN- $\alpha 2$ (500,000 IU) twice daily for 10 days and 15-intracervical injections of IFN- $\alpha 2$ (3,000,000 IU) everyother-day. In the end of IFN-TRT, patient experienced weakness, rapid fatigability and other symptoms of AIT progression and a noticeable abnormal enlargement of the thyroid glands and she went back to the endocrinologist, who registered progression of AIT with abnormal enlargement of thyroid gland lobules: left till $24.3 \mathrm{~cm}^{3}$, and right $-17.8 \mathrm{~cm}^{3}$ by ultrasound, with increased values of TSH-till $8.4 \mathrm{mIU} / \mathrm{L}$ (Table 1). In order to stop progression of AIT daily dose of L-thyroxin was increased till $150 \mathrm{mg}$. An IFN-TRT was immediately halted. After 7 months HPV infection spontaneously disappeared and after 1 year patient had a baby.

\section{DISCUSSION}

In our case, unfortunately the gynecologist was not aware about possibility of IFN-induced thyroiditis development, especially in this patient with thyroid hypofunction and

Table 1. Patient condition, size of thyroid glands, concentration of thyrotropin hormone (TSH) and daily dose of L-Tyroxine before and after interferon treatment (IFN-TRT)

\begin{tabular}{|c|c|c|c|c|}
\hline \multirow{2}{*}{\multicolumn{2}{|c|}{ Parameters }} & \multicolumn{2}{|c|}{ IFN-TRT } & \multirow{2}{*}{ Outcome } \\
\hline & & before & after & \\
\hline \multicolumn{2}{|c|}{$\begin{array}{l}\text { Patient's condition with } \\
\text { background hormonal } \\
\text { replacement therapy }\end{array}$} & stabile & relapse & relapse \\
\hline \multirow{2}{*}{$\begin{array}{l}\text { Ultrasound size of } \\
\text { the thyroid gland } \\
\text { lobules, } \mathrm{cm}^{3}\end{array}$} & Left & 14.5 & 24.3 & up to $67.6 \%$ \\
\hline & Right & 15.1 & 17.8 & up to $27.0 \%$ \\
\hline \multicolumn{2}{|c|}{$\begin{array}{c}\text { TSH, mIU/L } \\
\text { (Reference values: } 0.4-4.5 \text { ) }\end{array}$} & 0.88 & 8.4 & $\begin{array}{l}\text { up to } 10 \\
\text { fold }\end{array}$ \\
\hline \multicolumn{2}{|c|}{ Dose of L-Tyroxine, mg } & 75 & 150 & up to 2 fold \\
\hline
\end{tabular}

AIT. Even, when patient complained on weakness, rapid fatigability and other symptoms of AIT progression and a noticeable abnormal enlargement of the thyroid glands treatment was prolonged. IFN-TRT was canceled when patient was consulted by endocrinologist and a noticeably enlargement of the thyroid glands was registered by ultrasound with increased values of TSH and there was necessity to substantially increase the daily dose of Ltyroxine treatment.

In general, the main reason of this case was commercialization and compartmentalization of medical services, aggressive marketing of pharmaceutical companies as well as lack of systemic postgraduate education of practitioners during last a quarter of a century in RF and CIS countries. More than 120 immune tropic agents were registered in RF, most of them without relevant results of randomized clinical trials. Consequently uncontrolled use of immune modulating drugs is a widespread events in a routine of physicians, even they did not know indications or contraindications of those medications [21]. Clinical guidelines concerning immune modulating medications were mostly written by engagement of pharmaceutical companies [22] and the meetings of professional societies are being an important platform to realize aggressive marketing campaigns of pharmaceutical industry as well as mass media is widely used to reach this purpose. Therefore, unfortunately physicians misinformed and this case was happened as a consequence of such paradoxical situation in healthcare systems of these countries.

The IFN-triggered dramatic enlargement of thyroid gland size and progression of its dysfunction in our patient was related with combination of two factors: a background AIT with thyroid hypofunction and the INF-TRT. This patient would not suffer this IFN side effect at all, if gynecologist was interested in a background condition of this patient and a possible dysfunction of IFN target organs before to prescribe IFN-TRT. In spite of short prolongation and lower dose of IFN-TRT in comparison with modes of cancer or hepatitis adjuvant IFN-TRT, background conditions of our patient with AIT and thyroid glands' hypofunction were contributing factors of IIT. These results correspond with findings according to review by Ward and Bing-You that in patients receiving IFN-TRT, identifiable risk factors for developing autoimmune thyroid dysfunction are preexisting overt thyroid or autoimmune disease, subclinical thyroid or autoimmune thyroid disease, and female gender [23].

IFN-induced destruction of thyroid cells and their function impairment were shown in thyroid cell culture and in vivo experiments. So, Caraccio, et al. in primary human thyrocyte cultures [24] demonstrated an inhibitory effect of both IFN- $\alpha / \beta$ on the TSH-stimulated gene expression of thyroid peroxidase (TPO), sodium/iodide 
symporter (NIS), and thyroglobulin (Tg) as well as free thyroxin $\mathrm{T}(4)$ release and concluded that the development of hypothyroidism during IFN-TRT may be related, at least in part, to an abnormal expression and function of key proteins involved in iodine uptake and organification [24].

Later Caraccio et al. in primary thyrocyte cultures showed that both IFNs increase apoptosis, indicating a possible pathway of development and progression of IFN-TRT-associated thyroid disease [25]. Based on these direct IFN thyroid effects and well-known basic IFNimmune mediated effects Tomer and Menconi proposed a pathogenesis of IIT (Figure 1) as [18]: "IFN- $\alpha$ direct thyroid toxic effects include upregulation of thyroidspecific proteins, such as thyroid stimulating hormone receptor (TSHR) gene, Tg, TPO, NIS expression, as well as induction of heat shock proteins (Hsp) expression, and thyroid cell death, whereas IFN- $\alpha$ immune effects include activation of immune cells, switching the immune response to Th1 pathways or cellular immune response, down regulation of regulatory $\mathrm{T}$ (Treg) cells, and induction of cytokine release e.g. interleukin (IL-6), and increased major histocompatibility complex (MHC) I expression. IFN- $\alpha$ also increases activity of immunocompetent cells such as lymphocytes, macrophages, NK-cells, neutrophils and monocytes. The combination of direct thyroid toxicity and immune stimulation can cause the release of thyroid auto-antigens and their presentation to resident T-cells, initiating an autoimmune response by a bystander mechanism” [18].

Although mechanisms of autoimmune reaction in IFNinduced destruction of thyroid cells during IFN-TRT are not clear yet. Recently many researches have supported hypothesis concerning the induction of thyroid autoimmunity by IFN-TRT.

Akeno et al. described a development of marked inflammatory thyroid destruction associated with immune cell infiltration of thyroid and surrounding tissues leading to profound hypothyroidism in transgenic mice [26]. Surprisingly, upregulation of pathways in transgenic mice thyroid glands was similar to those observed in cultured thyrocytes, which facilitated Akeno et al., to conclude that taken together, these results demonstrate that the induction of tissue inflammation and autoimmunity by IFN- $\alpha$ involves direct tissue toxic effects as well as provocation of destructive bystander immune responses [26].

It was shown, that independently of new IFNs implementation with improved pharmacokinetic and pharmacodynamic properties such as pegylated IFN their adverse effects were not diminished [27].

Minami et al. systematically reviewed with metaanalysis of the rates of IFN-TRT-related deaths and serious adverse events among 27,569 patients and concluded that the mortality rate during IFN-TRT was acceptably low, but the rate of serious adverse events was not negligible in a treatment for a benign disease [28].

Recently, Tran et al in their review, summarized the worldwide current management and follow-up guidelines for patients undergoing IFN-TRT and suggested monthly screening test with TSH level whilst receiving combined ribavirin and IFN- $\alpha$-TRT [29]. In a case of abnormal TSH levels recommend to sequentially evaluate free thyroid hormone parameters.

Owing to wide range of IFN-TRT side effects and doubtful IFN-TRT benefits in patients with genital warts and HPV-associated lesions [19], we speculate that

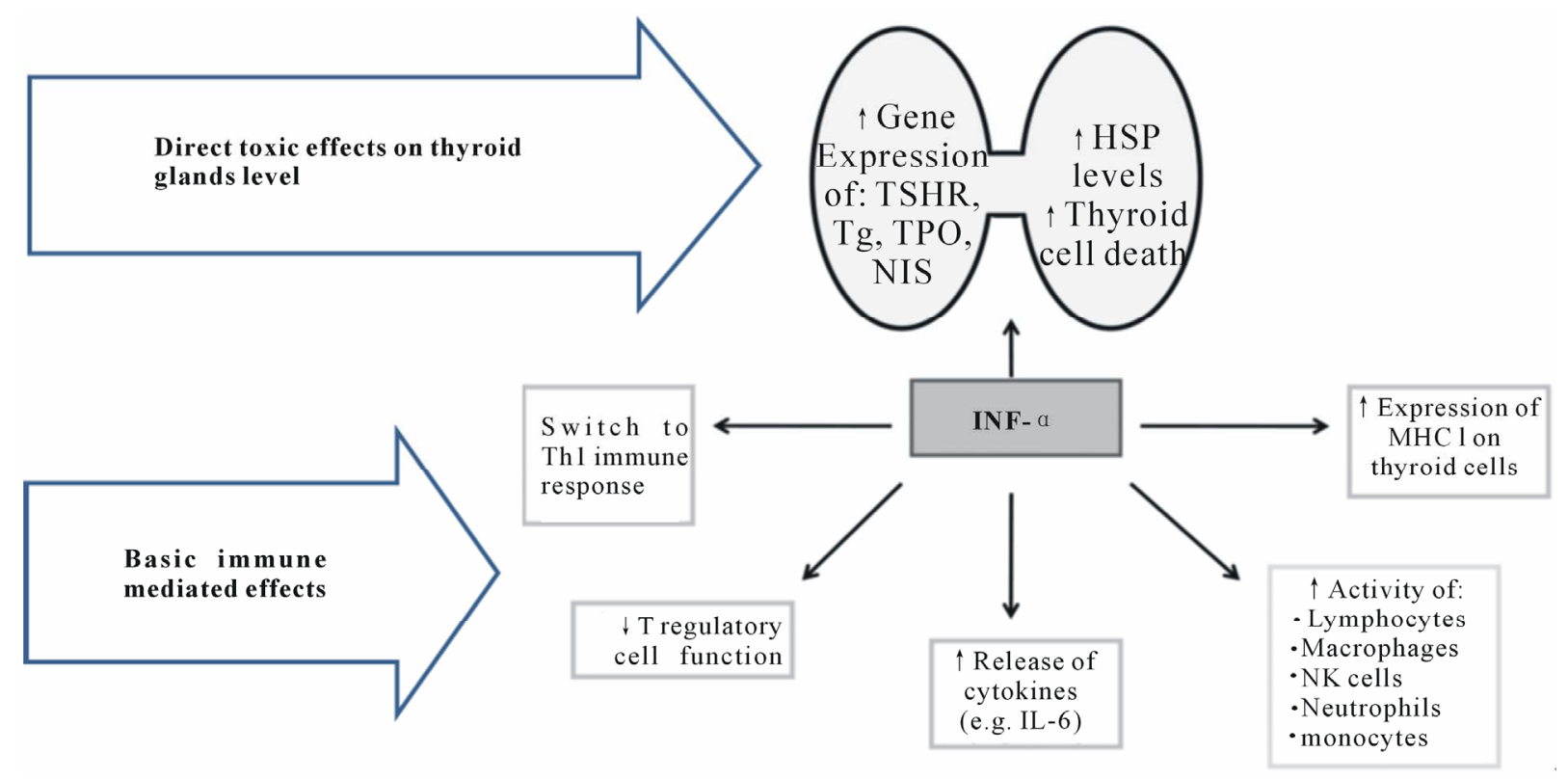

Figure 1. IFN-induced direct thyroid toxic and basic immune mediated effects. (Modified from Tomer and Menconi [18]) 
IFN-TRT in gynecological patients should be used only in cases of special needs with monitoring a function of IFN-target organs such as thyroid glands.

\section{CONCLUSION}

On the basis of this observation and a brief review of literature we suggest that the potential adverse effects of interferon therapy are overbalanced than its benefits for gynecological patients, therefore any interferon treatment should be recommended with strict indications as well as after screening of conditions and functions of thyroid glands and other interferon target organs to avoid interferon treatment side effects. Practitioners especially gynecologists should inform their patients about pleiotropic interferon effects and its high frequent and wide range side effects before to start such kind of treatment.

\section{REFERENCES}

[1] Rozati, S., Naef, L., Levesque, M.P., French, L.E. and Dummer, R. (2012) Real-life experience with pegylated interferon and conventional interferon in adjuvant melanoma therapy. Journal of Immunotherapy, 36, 52-56.

[2] Inman, B.A., Harrison, M.R. and George, D.J. (2012) Novel immunotherapeutic strategies in development for renal cell carcinoma. European Urology, in Press. doi:10.1016/j.eururo.2012.10.006

[3] Coppin, C., Porzsolt, F., Awa, A., Kumpf, J., Coldman, A. and Wilt, T. (25 January 2005) Immunotherapy for advanced renal cell cancer. Cochrane Database of Systematic Reviews, Article ID: CD001425.

[4] Ruiz-Delgado, G.J., Tarin-Arzaga, L.C., Alarcon-Urdaneta, C., Calderon-Garcia, J., Gomez-Almaguer, D. and Ruiz-Arguelles, G.J. (2012) Treatment of hairy cell leukemia: Long-term results in a developing country. Hematology, 17, 140-143.

doi:10.1179/102453312X13376952196331

[5] Regnier-Rosencher, E., Guillot, B. and Dupin, N. (2012) Treatments for classic Kaposi sarcoma: A systematic review of the literature. Journal of the American Academy of Dermatology, 68, 313-331.

[6] Chen, Y.S., Yi, W. and Jiang, K. (2012) Effects of antiviral nucleotide/nucleoside analogues and interferon on hepatitis B virus-related liver cirrhosis: A meta-analysis. Zhonghua Gan Zang Bing Za Zhi, 20, 811-816.

[7] Chayama, K., Hayes, C.N., Ohishi, W. and Kawakami, Y. (2012) Treatment of chronic hepatitis $C$ virus infection in Japan: Update on therapy and guidelines. Journal of Gastroenterology, 48, 1-12.

[8] Enudi, W. and Udolu, O.J. (2009) Neuropsychiatric complications associated with interferon-alpha-2b treatment of malignant melanoma. African Journal of Psychiatry (Johannesbg), 12, 227-228.

[9] McNutt, M.D., Liu, S., Manatunga, A., Royster, E.B., Raison, C.L., Woolwine, B.J., Demetrashvili, M.F., Miller, A.H. and Musselman, D.L. (2012) Neurobehavioral effects of interferon-alpha in patients with hepatitis-C: Symptom dimensions and responsiveness to paroxetine. Neuropsychopharmacology, 37, 1444-1454. doi:10.1038/npp.2011.330

[10] Malaguarnera, M., Vicari, E., Calogero, A., Cammalleri, L., Di, F.I., Gargante, M.P., Pennisi, G., Risino, C., Ranno, S. and Rampello, L. (2008) Sexual dysfunction in chronic hepatitis $\mathrm{C}$ virus patients treated with interferon alpha and ribavirin. Journal of Interferon \& Cytokine Research, 28, 603-609. doi:10.1089/jir.2008.0021

[11] Dove, L.M., Rosen, R.C., Ramcharran, D., Wahed, A.S., Belle, S.H., Brown, R.S. and Hoofnagle, J.H. (2009) Decline in male sexual desire, function, and satisfaction during and after antiviral therapy for chronic hepatitis C. Gastroenterology, 137, 873-884.

[12] Argiris, A., Agarwala, S.S., Karamouzis, M.V., Burmeister, L.A. and Carty, S.E. (2008) A phase II trial of doxorubicin and interferon alpha $2 \mathrm{~b}$ in advanced, non-medullary thyroid cancer. Invest New Drugs, 26, 183-188. doi:10.1007/s10637-007-9091-2

[13] Kose, S., Gozaydin, A., Akkoclu, G. and Ece, G. (2012) Chronic hepatitis B with type I diabetes mellitus and autoimmune thyroiditis development during interferon alpha therapy. The Journal of Infection in Developing Countries, 6, 364-368.

[14] Andrade, L.J., Atta, A.M., Atta, M.L., Mangabeira, C.N. and Parana, R. (2011) Thyroid disorders in patients with chronic hepatitis C using interferon-alpha and ribavirin therapy. Brazilian Journal of Infectious Diseases, 15, 377-381. doi:10.1590/S1413-86702011000400013

[15] Menconi, F., Hasham, A. and Tomer, Y. (2011) Environmental triggers of thyroiditis: Hepatitis $\mathrm{C}$ and interferonalpha. Journal of Endocrinological Investigation, 34, 7884

[16] Fentiman, I.S., Thomas, B.S., Balkwill, F.R., Rubens, R.D. and Hayward, J.L. (1985) Primary hypothyroidism associated with interferon therapy of breast cancer. Lancet, 1, 1166.

[17] Oppenheim, Y., Kim, G., Ban, Y., Unger, P., Concepcion, E., Ando, T. and Tomer, Y. (2003) The effects of alpha interferon on the development of autoimmune thyroiditis in the NOD H2h4 mouse. Clinical and Developmental Immunology, 10, 161-165. doi:10.1080/10446670310001642177

[18] Tomer, Y. and Menconi, F. (2009) Interferon induced thyroiditis. Best Practice \& Research: Clinical Endocrinology \& Metabolism, 23, 703-712. doi:10.1016/j.beem.2009.07.004

[19] Buck, H.W., Jr. (2010) Genital warts. Clinical Evidence, 2010, PMC3217761.

[20] Yang, J., Pu, Y.G., Zeng, Z.M., Yu, Z.J., Huang, N. and Deng, Q.W. (2009) Interferon for the treatment of genital warts: A systematic review. BMC Infectious Diseases, 9, 156. doi:10.1186/1471-2334-9-156

[21] Mynbaev, O.A. and Eliseeva, M.Y. (2011) The scoring scale of researches' cogency devoted to efficacy of immunomodulators from the position of evidence-based medicine. Siberian Journal of Oncology, N6, 70-73. (Rus.) 
[22] Mynbaev, O.A., Eliseeva, M.Y. and Chernov, A.V. (2011) Lapsus creativus or sciolistic daydreaming (Manilovshina). Z Turbotoyu pro Zhinku, 3, 32-34. (Rus.)

[23] Ward, D.L. and Bing-You, R.G. (2001) Autoimmune thyroid dysfunction induced by interferon-alpha treatment for chronic hepatitis C: Screening and monitoring recommendations. Endocrine Practice, 7, 52-58.

[24] Caraccio, N., Giannini, R., Cuccato, S., Faviana, P., Berti, P., Galleri, D., Dardano, A., Basolo, F., Ferrannini, E. and Monzani, F. (2005) Type I interferons modulate the expression of thyroid peroxidase, sodium/iodide symporter, and thyroglobulin genes in primary human thyrocyte cultures. The Journal of Clinical Endocrinology \& Metabolism, 90, 1156-1162. doi:10.1210/jc.2004-1173

[25] Caraccio, N., Cuccato, S., Pratesi, F., Dardano, A., Ursino, S., Chimenti, D., Boldrini, L., Materazzi, G., Migliorini, P. and Monzani, F. (2009) Effect of type I interferon(s) on cell viability and apoptosis in primary human thyrocyte cultures. Thyroid, 19, 149-155. doi:10.1089/thy.2008.0290

[26] Akeno, N., Smith, E.P., Stefan, M., Huber, A.K., Zhang,
W., Keddache, M. and omer, Y. (2011) IFN-alpha mediates the development of autoimmunity both by direct tissue toxicity and through immune cell recruitment mechanisms. The Journal of Immunology, 186, 4693-4706. doi:10.4049/jimmunol.1002631

[27] Simin, M., Brok, J., Stimac, D., Gluud, C. and Gluud, L.L. (2007) Cochrane systematic review: Pegylated interferon plus ribavirin vs. interferon plus ribavirin for chronic hepatitis C. Alimentary Pharmacology \& Therapeutics, 25, 1153-1162. doi:10.1111/j.1365-2036.2007.03294.X

[28] Minami, T., Kishikawa, T., Sato, M., Tateishi, R., Yoshida, H. and Koike, K. (2012) Meta-analysis: Mortality and serious adverse events of peginterferon plus ribavirin therapy for chronic hepatitis C. Journal of Gastroenterology, 48, 254-268.

[29] Tran, H.A., Jones, T.L., Ianna, E.A., Foy, A. and Reeves, G.E. (27 November 2012) Thyroid disease in chronic hepatitis $\mathrm{C}$ infection treated with combination interferonalpha and ribavirin: Management strategies and future perspective. Endocrine Practice, 1-33. 